\title{
A PRESENÇA DA FRATERNIDADE NA (RE)ORGANIZAÇÃO DA CONVIVÊNCIA HUMANA: uma abordagem literária e realista
}

\author{
Ildete Regina Vale da Silva* \\ Samantha Sabrine dos Santos**
}

\section{RESUMO}

Este artigo tem como tema a reflexão sobre a importância da Fraternidade na (re)organização da convivência humana valendo-se, para tanto, de duas abordagens: uma literária sobre a obra Ensaio sobre a cegueira, e outra realista sobre a Pandemia da Covid-19. O objetivo do estudo consiste em identificar a Fraternidade no romance e analisar o grau de importância dessa na organização da convivência humana tanto no cenário literário, quanto frente à concretização da ameaça à Humanidade com a Covid-19. Utiliza-se na Investigação o Método Indutivo, no Tratamento de dados o Método Cartesiano e no Relatório dos Resultados a Base Lógica Indutiva.

Palavras-chave: Fraternidade. Humanidade. (Re)organização da Convivência Humana. Pandemia da Covid-19. Ensaio sobre a cegueira.

\section{THE PRESENCE OF FRATERNITY IN THE (RE)ORGANIZATION OF HUMAN LIVING: a literary and realistic approach}

\begin{abstract}
This article focuses on the reflection about the importance of the Fraternity in the (re)organization of human living, using two approaches: a literary one on the Blindness, and a realistic one on the Pandemic of Covid-19. The objective of the study is to identify the Fraternity in the novel and analyze its importance in the organization of human living in the literary scene, and in view of the realization of the threat to Humanity with Covid-19. The Inductive Method is used in the Investigation, the Cartesian Method in the Data Treatment and the Inductive Logical Base in the Results Report.
\end{abstract}

Keywords: Fraternity. Humanity. (Re)organization of Human Living. Covid-19 Pandemic. Blindness.

\section{INTRODUÇÃO}

\footnotetext{
* Dottore di Ricerca in Diritto pubblico nella Università degli Studi de Perugia - Itália, Doutora em Ciência Jurídica pela Universidade do Vale do Itajaí - UNIVALI (2014) e mestre pelo mesmo Programa de PósGraduação Stricto Sensu em Ciência Jurídica da UNIVALI, Itajaí/SC (2009). Especialista em Direito do Trabalho. Autora do livro "Constituição e Fraternidade: o Valor Normativo do Preâmbulo da Constituição". http://orcid.org/0000-0003-4671-0457. Advogada. E-mail: ildetervs@gmail.com

** Mestranda em Ciência Jurídica pelo Programa de Pós-Graduação Stricto Sensu da Universidade do Vale do Itajaí - UNIVALI, Especialista em Direito de Família e Sucessões pela UNIASSELVI, Graduada em Direito pela Universidade Regional de Blumenau - FURB. http://orcid.org/0000-0002-2152-7253. Advogada. E-mail: samantha-sabrine@hotmail.com.
} 
O presente artigo tem como tema central instigar uma reflexão sobre a importância da Fraternidade na (re)organização da convivência humana valendo-se, para tanto, de duas abordagens: uma literária sobre a obra Ensaio sobre a cegueira, e outra realista sobre a Pandemia da doença causada pelo novo coronavírus - Covid-19.

A dupla abordagem se justifica por dois motivos: primeiro porque de forma ímpar, na obra Ensaio sobre a cegueira, José Saramago priva as personagens dos seus direitos fundamentais mais básicos, reduzindo-as as suas essências, desorganizando e desconstruindo o modelo de Sociedade que até então se conhecia. Assim, em meio a uma situação extrema em que, acometidos por uma moléstia aparentemente contagiosa, - quase - todos cegam temporariamente, o enredo se torna o laboratório perfeito para analisar a importância da presença da Fraternidade como condição de possibilidade na (re)organização da convivência humana.

Segundo porque, muito semelhante ao romance saramaguiano, a pandemia do novo coronavírus - Covid-19 também apanhou a Humanidade desapercebida, ocasionando um estado de sujeição e fragilidade que, de certa forma, também tem resultado na desorganização da Sociedade, na desconstrução do modelo que se conhecia antes da pandemia, obrigando as pessoas a se reorganizarem no modo de vida e de convivência, que até se tem popularmente designado como o novo normal.

Assim, a problemática funda-se em saber se é possível notar traços da presença da Fraternidade no romance saramaguiano e o grau de importância desta na (re)organização da vida em comum, na convivência humana com sentido daquilo que é realmente inerente à existência com dignidade tanto no cenário literário, quanto frente à concretização da ameaça à Humanidade com a Pandemia do novo coronavírus - Covid-19.

O objetivo deste estudo consiste em identificar traços da presença da Fraternidade na obra Ensaio sobre a cegueira e analisar o grau de importância deste sentimento de singular Humanidade na organização da vida em comum, na convivência humana com sentido daquilo que é realmente inerente à existência com dignidade tanto no cenário literário, quanto frente à concretização da ameaça à Humanidade com a Pandemia da Covid-19.

Revista de Direito, Arte e Literatura | e-ISSN: 2525-9911 | Encontro Virtual | v. 6 | n. 2 | p. 38 - 56 | Jul/Dez. 2020. 
Para atingir o objetivo proposto, inicialmente, tecem-se considerações sobre como a Pandemia causada pelo novo coronavírus - Covid-19 revelou à Humanidade sua vulnerabilidade e, paradoxalmente, o potencial positivo que pode ser extraído das inúmeras consequências. Na sequência, trabalha-se a presença da Fraternidade como condição de possibilidade na (re)organização da convivência humana, evidenciando-a como recurso para superar as situações de crise.

Para identificar a presença da Fraternidade, ilustra-se o presente artigo com a obra de José Saramago - Ensaio sobre a cegueira -, drama vivenciado pelas pessoas de uma cidade fictícia e inominada acometidas repentinamente pela epidemia de uma cegueira branca que, nas suas vulnerabilidades, protagonizam cenas que evidenciam um sentimento singular de Humanidade, com o objetivo de (re)organizarem a convivência.

Por certo, o presente artigo não objetiva exaurir a reflexão inerente à presença da Fraternidade na obra Ensaio sobre a cegueira, tampouco o debate da Fraternidade como recurso para enfrentar as situações de crise. Almeja-se, apenas, estimular as possibilidades de dialogar sobre a importância da Fraternidade na (re)organização da convivência humana, utilizando-se do referido romance em razão da atualidade latente das suas críticas sociais, e das consequências da Pandemia causada pelo novo coronavírus - Covid-19.

No que concerne à Metodologia utilizada, seguem-se os preceitos de Pasold (2018, p. 89-100) e utiliza-se na fase de Investigação o Método Indutivo, na fase de Tratamento de dados o Método Cartesiano e no Relatório dos Resultados a Base Lógica Indutiva. Nas fases da Pesquisa, foram acionadas as Técnicas do Referente, da Categoria, do Conceito Operacional e da Pesquisa Bibliográfica.

\section{CONSIDERAÇÕES INICIAIS}

Na despedida do ano de 2019, mal sabia a Humanidade que o ano novo muito cedo se tornaria conhecido como aquele em que teve início a maior crise contemporânea da Humanidade, concretizando os temores que já eram sentidos simultaneamente, em razão da Globalização, pela ameaça constante de uma guerra nuclear ou pela finitude dos recursos naturais.

Revista de Direito, Arte e Literatura | e-ISSN: 2525-9911 | Encontro Virtual | v. 6 | n. 2 | p. 38 - 56 | Jul/Dez. 2020. 
A Pandemia causada pelo novo coronavírus - Covid-19 em um piscar de olhos revelou à Humanidade sua vulnerabilidade frente a um vírus microscópico, confrontando a pretensa onipotência que creditava ter:

\begin{abstract}
A cultura dominante da civilização tecnocientífica fez com que parte da humanidade acreditasse não só na onipotência das tecnologias, mas que os próprios seres humanos detinham o controle de todas as esferas da vida. Entretanto, como é possível observar desde a emergência da pandemia de covid 19, apesar do avanço tecnológico das últimas décadas, marcado pelo desenvolvimento da biotecnologia, da inteligência artificial e da informática, "um microscópico vírus nos faz cair de bruços em nossa impotência frente a ele”, [...]. (PEREZ TAPIAS ${ }^{3}$, IHU, 2020).
\end{abstract}

Inúmeras são as consequências da crise pandêmica, porém, essas podem ter um potencial positivo, na avaliação de Perez Tapias (IHU, 2020):

[...], a amplitude da crise sanitária, que trouxe inúmeras consequências para outras esferas da vida individual e coletiva, também pode ter um potencial positivo na medida em que nos fez "redescobrir socialmente o valor do comum", como a saúde, a educação e a democracia. Em definitivo, o comum se assenta em uma natureza humana comum, base ontológica para abordar objetivos políticos de igualdade social e de gênero e exigências morais de igualdade de tratamento. Sem a convicção de que todos somos igualmente humanos, isto é, que não há humanos que sejam mais humanos do que outros, os objetivos de igualdade não se sustentam.

A letalidade do novo coronavírus - Covid-19 instiga a refletir e reverter a ideologias oriundas do "individualismo burguês da modernidade ocidental" (PEREZ TAPIAS, IHU, 2020), de uma Sociedade de classes, da crença que o único caminho a seguir seria o do crescimento econômico, de padrões e comportamentos do consumo pelo consumo, da onipotência da revolução tecnológica; tudo em detrimento do que, realmente, dá sentido à existência da Humanidade e que, para este estudo em específico, é a presença da Fraternidade na (re)organização da convivência humana.

\title{
3 A PRESENÇA DA FRATERNIDADE NA (RE)ORGANIZAÇÃO DA CONVIVÊNCIA HUMANA
}

\footnotetext{
3 José Antonio Perez Tapias. decano da Faculdade de Filosofia e Letras da Universidade de Granada, na Espanha.
}

Revista de Direito, Arte e Literatura | e-ISSN: 2525-9911 | Encontro Virtual | v. 6 | n. 2 | p. 38 - 56 
Frequentemente associa-se a ideia de Fraternidade à campanha anual promovida especialmente durante a quaresma pela Igreja Católica ou à Revolução Francesa de 1789 e seus ideais iluministas: Liberté, Égalité, Fraternité.

Ocorre que a ideia da Fraternidade está muito mais presente na convivência humana do que acredita o senso comum, pois, pode-se encontrá-la na Declaração Universal dos Direitos Humanos (DUDH); no preâmbulo da Constituição da República Federativa do Brasil de 1988 (CRFB/88); no núcleo dos direitos fundamentais de terceira dimensão, chamados difusos ou coletivos - concebidos não para a proteção individual da pessoa, mas para a coletividade - como o direito ao meio ambiente ecologicamente equilibrado, à autodeterminação dos povos, à preservação do patrimônio histórico e cultural, ao desenvolvimento, à paz, entre outros (MENDES, BRANCO, 2018, p. 201).

Considera-se que a tríade consagrada no decorrer do tempo, principalmente após a Revolução Francesa, detém uma síntese cultural e um referencial teórico e prático ainda inédito à Humanidade. A articulação desse triplo imperativo sintetiza uma fórmula excepcionalmente eficaz à teoria e à prática não devidamente explorada como pressuposto da cultura do universalismo político (BAGGIO, 2012, p.12.):

\footnotetext{
A Fraternidade já detinha um referencial teórico com elementos conceituais que melhor representava a interdependência entre homens e, embora a expressão de sentimento tenha sido entendida como limite, esse entendimento não tende mais a subsistir, porque é, justamente, a ausência do sentimento que tem sido tão cara a Humanidade. (VALE DA SILVA, BRANDÃO, 2017, p. 53).
}

Ademais, a Fraternidade entendida como princípio do universalismo político tem um conceito mais amplo que a solidariedade (VALE DA SILVA, BRANDÃO, 2015, p. 109) e pode ser entendida como um sentimento de união, convivência harmônica e responsabilidade das pessoas para com elas mesmas. Indo além, descreve-se uma Sociedade Fraterna como:

[...] a Sociedade que tem como bem social o sentido da existência do Humano. É o tipo de Sociedade construída por Pessoas Humanas estimuladas a perceber o sentido da própria existência e porque percebem o sentido da própria existência, adotam modos de vida que dão sentido à existência do Humano e sua continuidade no tempo e espaço da biosfera. (VALE DA SILVA, BRANDÃO, 2015, p. 151).

No sistema constitucional brasileiro, a Fraternidade "tem status de categoria estratégica e relevante na formação da cultura constitucional pela qualidade que confere à Sociedade no texto do preâmbulo" (VALE DA SILVA, BRANDÃO, 2017, p. 54), uma 
perspectiva que resgata a força que há na estrutura conceitual desta categoria na relação de interdependência com a Liberdade e a Igualdade.

Advoga-se a tese de que a Fraternidade é um importante fundamento da cultura ocidental e um referencial principiológico que propaga a tradição humanista:

\begin{abstract}
A civilização ocidental pode e deve propagar o que tem de melhor: a tradição humanista, o pensamento crítico e o pensamento autocrítico, os princípios democráticos, os direitos da mulher, da criança e do homem. As sociedades tradicionais mantêm uma relação com a Natureza, um sentido de inclusão no Cosmo, laços sociais comunitários que devem conservar, mesmo introduzindo nelas o que existe de melhor do Ocidente. (MORIN, 2013, p. 61).
\end{abstract}

Assim, encontra-se na Fraternidade uma essência principiológica com o condão de recuperar "o sentimento de singular humanidade" (RESTA, 2004, p.13), tão caro aos desafios impostos à Humanidade. Constituindo, então, uma categoria política e jurídica com condição de possibilidade para melhor representar "a convivência entre Pessoas Humanas nas diferentes projeções de organização da vida em Sociedade". (VALE DA SILVA, BRANDÃO, 2017, p. 53).

Não há dúvidas de que a Fraternidade é um dos princípios do universalismo político que ascendeu na Modernidade, porém, no desenrolar dessa, também foi negligenciada no pensamento político e jurídico (VALE DA SILVA, BRANDÃO, 2015, p. 89-105). O projeto da Modernidade influenciou políticas e “indicou princípios normativos através do racionalismo puro, identificados como positivismo" (VALE DA SILVA, BRANDÃO, 2015, p.101).

Assim, no desenrolar dos acontecimentos, o esquecimento da Fraternidade no cenário político pode ser atribuído, entre outros fatores, ao prevalecimento de um sentido distorcido da individualização, que mais fez reproduzir um sentimento de individualismo do que de individualidade ${ }^{4}$ :

A "individualização" agora significa uma coisa muito diferente do que significava há cem anos e do que implicava nos primeiros tempos da era moderna - os tempos

\footnotetext{
4 No minidicionário Houaiss da língua portuguesa (2019, p. 456) individualidade é característica do que é individual; singularidade; conjunto de atributos que diferencia um indivíduo ou uma coisa; identidade. Individualismo é tendência a considerar apenas os valores e os interesses individuais; egoísmo. E individualização é ação ou efeito de individualizar; processo pelo qual um organismo, especialmente um indivíduo, se torna diferente de todos os outros.
}

Revista de Direito, Arte e Literatura | e-ISSN: 2525-9911 | Encontro Virtual | v. 6 | n. 2 | p. 38 - 56 | Jul/Dez. 2020. 
da exaltada "emancipação" do homem da trama estreita da dependência, da vigilância e da imposição comunitárias. (BAUMAN, 2001, p. 39-40).

Acredita-se, então, que o processo de individualização na Sociedade deva ser ressignificado positivamente para estar relacionado ao respeito do indivíduo na qualidade de pessoa: o prestígio da autonomia da vontade, o exercício dos direitos de cidadania, a garantia dos direitos fundamentais, o liberalismo,... e não ao individualismo e ao egocentrismo.

A individualidade é um elemento do bem social, contudo, sem qualquer desprezo aos benefícios da perfeição dos métodos e práticas, pouco espaço tem sido deixado para que a Pessoa Humana possa “estruturar o seu mundo, a sua personalidade. A espontaneidade individual, valor intrínseco da individualidade, parece não ter objetivo para se desenvolver, [...]" (VALE DA SILVA, BRANDÃO, 2015, p.165), levando a Pessoa Humana a acreditar que é pequena individualmente e por essa razão não seria capaz de alcançar algo grande, tornando-a vulnerável nos seus interesses diante da dificuldade de "discernir quando está agindo por sua própria convicção ou pela opinião pública” (VALE DA SILVA, BRANDÃO, 2015, p.166).

Em um contexto de verdades presumidas, de conhecimento compartimentalizado, produzido sem maiores reflexões sobre a realidade social e onde o interesse dos poderes dominantes manipula muito facilmente a opinião pública, tudo parece contribuir para a incapacidade da Pessoa Humana de aceitar a "diversidade e de conceber que a essencialidade de ser humana consiste em aceitar que pessoas diferentes possam viver vidas diferentes" (VALE DA SILVA, BRANDÃO, 2015, p.166).

Fundamental é entender que a ideia atual de Sociedade remete à diversidade (de pessoas, culturas, etnias, nacionalidades...) e que seu limite vai muito além do pensamento individual e da soberania dos Estados, que já se sabe estar desgastada na sua forma de "pertenças fechadas, governadas por um mecanismo ambíguo que inclui os cidadãos, excluindo todos os outros" (RESTA, 2004, p. 12).

A necessidade de se resgatar o pensamento da Fraternidade é muitas vezes mais bem percebida em "tempos sombrios" (ARENDT, 2008, p. 20), pois é curioso como "[...] o medo adquire um ímpeto e uma lógica de desenvolvimento próprios [...]” (BAUMAN, 2007, p.15). Observa-se que Hannah Arendt, ao escrever sobre os regimes totalitários, discorreu sobre o 
sentimento que se evidenciava principalmente entre as pessoas submetidas às situações de degradação e crueldade:

[...] Tudo isso é apenas uma forma de dizer que o humanitarismo da fraternidade dificilmente condiz com os que não pertencem aos insultados e injuriados e que só podem dela partilhar através de sua compaixão. [...] Em tal estado de ausência de mundanidade e realidade, é fácil concluir que o elemento comum a todos os homens não é o mundo, mas a "natureza humana" [...] (ARENDT, 2008, p. 24).

Assim, a Fraternidade - aqui entendida como "sentimento singular de humanidade" (RESTA, 2004, p.13) - é evidenciada como recurso para superar as situações de crise, podendo ser o ideal fraterno, como aduziu o Ministro do Supremo Tribunal Federal Luiz Edson Fachin ao prefaciar a obra de Reynaldo Soares da Fonseca, Ministro do Superior Tribunal de Justiça: “[...] o antídoto que administra o soro da alteridade” (FONSECA, 2019, p. 14) e, essa é uma questão que pode ser bem compreendida na obra de José Saramago: Ensaio sobre a cegueira.

\section{JOSÉ SARAMAGO E A OBRA ENSAIO SOBRE A CEGUEIRA}

O brilhantismo de José de Souza Saramago, escritor lusitano galardoado com inúmeros prêmios literários - dos mais provincianos aos mais renomados, incluindo certamente suas maiores honrarias: Prêmio Camões em 1995 e Prêmio Nobel de Literatura em 1998 (LOPES, 2010, p. 240) - é gritante na obra Ensaio sobre a cegueira, esse que talvez seja seu trabalho mais reconhecido devido às traduções diversas e à exitosa adaptação para o cinema sob a direção do brasileiro Fernando Meirelles.

Autodidata na ciência literária (LOPES, 2010, p. 31) e com sua marca inconfundível de "escrita corrida" ao utilizar vírgulas para substituir sinais de pontuação, José Saramago levou quatro anos para escrever o romance que foi publicado em 1995 (LOPES, 2010, p. 151). Abalizado pelo antropocentrismo e repleto de críticas à Sociedade e ao comportamento humano, não se pode ignorar que por detrás do enredo repousa o clamor pessoal de José Saramago pela dignificação dos seres humanos e de uma sociedade mais justa "onde a pessoa seja a prioridade absoluta" (SARAMAGO, FJS, 2008): 
Em consequência da atribuição do Prémio Nobel a minha actividade pública viu-se incrementada. Viajei pelos cinco continentes, oferecendo conferências, recebendo graus académicos, participando em reuniões e congressos, tanto de carácter literário como social e político, mas, sobretudo, participei em acções reivindicativas da dignificação dos seres humanos e do cumprimento da Declaração dos Direitos Humanos pela consecução de uma sociedade mais justa, onde a pessoa seja prioridade absoluta, e não o comércio ou as lutas por um poder hegemónico, sempre destrutivas. (SARAMAGO, FJS, 2008).

O próprio Autor em sua autobiografia, ao mencionar as causas que abraçou durante a vida, enalteceu sua participação em ações que reivindicassem os direitos humanos (SARAMAGO, FJS, 2008). Justamente em virtude de seu engajamento social, que também foi abordado na biografia escrita por João Marques Lopes (2010, p. 28) como um “[...] sentimento de revolta ante as miudezas e as coisas graúdas necessariamente inscritas nas desigualdades sociais [...]" é que se pode afirmar que o brilharete de José Saramago ultrapassou a esfera literária e influiu irrefutavelmente sobre a política e a cidadania - e por que não dizer, também, sobre o Direito!?

Quanto à obra que se passa a analisar, o enredo cinge o drama vivenciado pelas pessoas de uma cidade fictícia e inominada acometidas repentinamente pela epidemia de uma "cegueira branca", cuja causa e natureza da afecção não se consegue diagnosticar. O roteiro com os detalhes precisos inerentes ao estilo saramaguiano inicia no primeiro caso de cegueira, quando o motorista parado ao sinal anuncia que está cego (SARAMAGO, 2019, p. 12), descendo uma ladeira angustiante de "despimento" das personagens e desconstrução da Sociedade na medida em que todos da localidade vão se contaminando até o contágio completo da população, ocasião em que o Autor passa a propor uma nova forma de organização social onde as pessoas são o que elas realmente são (SARAMAGO, 2019, p. 262).

As vivências e detalhes são descritos através de uma única personagem que, inexplicavelmente, não sucumbiu à "treva branca": a Mulher do médico. O que nos leva a crer que ela tenha sido deixada ilesa de forma proposital pelo Autor, por ser "os olhos" do leitor e, considerando a finalidade deste artigo, por protagonizar cenas que evidenciam um sentimento singular de Humanidade, de Fraternidade.

O nível alarmante de contágio do "mal-branco", cuja etiologia não se conseguia esclarecer, gerava pavor na população não contaminada, o que resultou em um ato extremo do governo, na pessoa do ministro, quando este resolveu submeter os então contaminados e os 
suspeitos de contágio (pessoas que tiveram contato com outras que cegaram) à quarentena forçada em um manicômio desativado enquanto não fosse descoberto um tratamento ou vacina para impedir que mais pessoas se contaminassem:

\footnotetext{
Em palavras ao alcance de toda a gente, do que se tratava era de pôr de quarentena todas aquelas pessoas, segundo a antiga prática, herdada dos tempos da cólera e da febre amarela, quando os barcos contaminados ou só suspeitos de infecção tinham de permanecer ao lardo de quarenta dias, até ver. (SARAMAGO, 2019, p. 45).
}

Impedidos de deixar as instalações, os cegos e os assintomáticos que tiveram contato com cegos são inicialmente separados em camaratas e regidos por sua própria sorte, pois, não há supervisores ou médicos para tratá-los - apesar de uma das personagens internadas ser oftalmologista, mas, mesmo que ansiasse exercer seu ofício, pouca serventia teria, haja vista que também não enxergava -. Outrossim, os internos foram privados desde o primeiro momento às necessidades mais básicas como higiene e água limpa.

Quanto à alimentação, no princípio a comida era racionada e enviada aos internos durante o dia pelos militares que faziam a segurança externa do local, no entanto, na medida em que a quantidade de cegos aumentava - que se estima ao final ter chegado ao número de trezentas pessoas (SARAMAGO, 2019, p. 278) -, seja porque os assintomáticos converteramse em cegos ou porque mais cegos do mundo exterior foram inseridos no hospício, a comida passou a ser o estopim da desarmonia do manicômio. Os internos, de uma maneira geral, tornam-se protagonistas dos comportamentos mais repugnantes e primitivos, beirando o caos e a barbárie quando reduzidos a sua essência e movidos apenas pela satisfação de suas necessidades fisiológicas.

Passado um lapso temporal considerável, quando os internos deixam o manicômio porque já não há mais vigilância dos militares, percebem que todos da localidade tornaram-se cegos e que o mundo está tomado por um caos absoluto. Então, entre o êxodo do manicômio e o desfecho da obra, a situação aparenta piorar um pouco mais porque não se pode negar que tanto as personagens quanto os leitores esperançavam que o mundo exterior ainda estivesse “digno", mas, infelizmente, não era essa a realidade, “[...] não havia diferença entre o fora e o dentro, entre o cá e o lá [...]" (SARAMAGO, 2019, p. 233).

Ninguém mais exercia suas funções, não havia fornecimento de energia elétrica, nem comida (SARAMAGO, 2019, p. 244), o sistema de saneamento básico estava colapsado, as 
ruas imundas, "[...] a civilização tinha regressado às primitivas fontes de chafurdo." (SARAMAGO, 2019, p. 263). Quanto às pessoas, estas vagavam cegas e desatinadas pelas ruas, procurando vestígios de comida, seus familiares, suas casas.

Tanto estavam desatinadas as pessoas que cegaram aleatoriamente na rua e não conseguiam encontrar o caminho de volta, como as que partiram do manicômio e agora também estavam na rua, porque não se olvida que muitos já entraram cegos na quarentena forçada e não tinham ciência de onde estava situado o manicômio, aliás, mesmo que tivessem, tal informação não teria muita utilidade, pois:

[...] não há comparação entre viver num labirinto racional, como é, por definição, um manicómio, e aventurar-se, sem mão de guia nem trela de cão, no labirinto dementado de cidade, onde a memória para nada servirá, pois apenas será capaz de mostrar a imagem dos lugares e não os caminhos para lá chegar. (SARAMAGO, 2019, p. 211).

Assim, é curioso que, paradoxalmente, o caminho de gradação ascendente até o ápice da obra - clímax - é a decida até o "fundo do poço", é a redução das personagens às suas essências e a desconstrução da Sociedade; um cenário de desespero e ausência quase que total de direitos fundamentais, diz-se "quase" porque ao menos o direito fundamental de "ir e vir" foi recobrado com o êxodo do manicômio, mesmo tendo pouca serventia tal direito quando não se sabe para onde.

A situação começa a mudar quando os protagonistas da obra, um pequeno grupo de sete pessoas (três homens, três mulheres e um menino) formado pelos primeiros a serem internados no manicômio, e liderados pela única personagem que não sucumbiu à moléstia (Mulher do médico), conforma-se com a condição de cegueira e passa, mais do que nunca, a ajudar-se mutuamente, despertando para o sentimento de responsabilidade um para com o outro.

A partir deste ponto pede-se vênia para abreviar a contextualização da obra porque uma melhor análise sobre o desfecho da trama será feita no tópico seguinte. Assim, limita-se a mencionar que a partir do clímax - a desconstrução total do tipo de Sociedade que se conhecia - o "tom" da obra se altera e o leitor recobra o fôlego, pois, os cegos acomodam-se na residência do médico e sua esposa e, seguros dos perigos do mundo exterior, começam a se adaptar ao novo estilo de vida, fazendo a angústia, que acompanhava a história até então, 
diminuir aos poucos até que, por fim, a obra termina com todas as personagens recuperando a visão.

Todavia, assim como o enredo da obra saramaguiana cinge a epidemia de cegueira, uma questão cinge este tópico: se nem todas as personagens que compunham o grupo se conheciam, e mesmo as que se conheciam - com exceção dos que eram casados entre si - não passavam de meros conhecidos, o que fez o grupo permanecer unido, ajudar-se mutuamente e (re)organizar sua própria convivência?

\section{A PRESENÇA DA FRATERNIDADE NA (RE)ORGANIZAÇÃO DA CONVIVÊNCIA NO ROMANCE SARAMAGUIANO}

Ao responder a pergunta, poder-se-ia dizer que, no primeiro momento da obra, o que possivelmente uniu o grupo foi o medo, a incerteza, ou até mesmo o fato de pertencerem a uma mesma camarata. Ocorre que após desconstruir a Sociedade por completo ao ponto de deixá-la inumana, ceifar os direitos fundamentais e reduzir as personagens a sua essência, Saramago propõe através do grupo uma nova forma de organização social, uma (re)organização baseada no trato responsável das pessoas para com elas mesmas, principalmente após o êxodo do manicômio, em que o objetivo passou a ser o bem estar comum do grupo: tentar viver com o máximo de dignidade possível diante daquele cenário perturbador.

O desfecho da brilhante obra de José Saramago é quando o grupo redescobre esse sentimento singular de Humanidade - de Fraternidade - e que o elemento comum entre eles não é a cegueira, mas a "condição humana". A partir desse momento, todas as personagens vão aos poucos recobrando a visão juntamente com o fôlego e a esperança dos leitores de que dali em diante será reerguida uma nova Sociedade, uma Sociedade Fraterna.

Partindo da premissa que só se pode recobrar o que foi perdido, é que se afirma que em meio ao grupo de cegos que recobraram a visão porque "redescobriram" o sentimento de Fraternidade está uma personagem "que nunca a perdeu" (SARAMAGO, 2019, p. 278): a Mulher do médico. Assim, considerando o que foi dito anteriormente sobre essa personagem ter sido deixada ilesa propositalmente pelo Autor, o que se propõe neste último tópico é uma 
análise mais específica da presença da Fraternidade, balizada pelas ações dessa mesma personagem.

Convém argumentar que o protagonismo conferido a ela neste quarto tópico não se deve apenas ao fato de enxergar, mas, à "[...] responsabilidade de ter olhos quando os outros os perderam [...]" (SARAMAGO, 2019, p. 241). A Mulher do médico protagonizou inúmeras cenas em que a consciência de Humanidade superou o fato de enxergar e foi além da aptidão física, caracterizando, irrefutavelmente, um sentimento de Fraternidade.

Logo no início da obra, quando surpreendidos ambos pela cegueira do médico, a personagem decide simular que está cega e adentrar na ambulância com o marido, cujo destino era um local incerto e não sabido, apenas para não o deixar só. Se o fez por amor, ou em virtude dos "deveres conjugais de esposa", pouco importa, porque a relevância está em ter ela chegado ao local, dado conta de que se tratava de um manicômio e ainda assim optar por permanecer. Talvez "optar" não seja a palavra exata porque bem se sabe que posteriormente teria uma ala do manicômio reservada para as pessoas que tiveram contato com os "contaminados".

De todo modo, a personagem, tendo ciência da situação, manifestou não apenas a vontade de ficar para ajudar o marido, mas também os outros cegos que viriam, antevendo que se trataria de um estado calamitoso. Afirmação que pode ser comprovada pelo trecho do diálogo entre marido e esposa que abaixo se acosta, em que é possível notar que, quando confrontada pelo marido sobre permanecer encarcerada naquele local mesmo com a visão conservada, a personagem opta por ficar, fazendo prevalecer a sua individualidade - no melhor sentido -, tomando uma decisão motivada por sua convicção:

Não te posso obrigar, Pois não, meu amor, não podes, fico para te ajudar, e aos outros que aí venham, mas não lhes digas que eu vejo, Quais outros, Com certeza não crês que vamos ser os únicos, Isto é uma loucura, Deve de ser, estamos num manicómio. (SARAMAGO, 2019, p. 48).

Observa-se no desenrolar da trama que laços são firmados pelo sentimento de pertencimento ao mesmo grupo, pela convivência e necessidade de organizá-la para própria sobrevivência, assim, poder-se-ia citar outras passagens, ainda no manicômio, onde mesmo aumentado muito o número de cegos encarcerados e estando ela também sofrendo as violências e privações dos direitos fundamentais, a Mulher do médico foi protagonista de 
outros atos de Humanidade; como para com a, então falecida, "cega das insônias", proporcionando a ela o tratamento mais digno que aquela ocasião permitira (SARAMAGO, 2019, p. 180).

O tempo e as experiências vividas no interior do manicômio recebem outros contornos quando acontece o êxodo. Neste sentido, infere-se que - em razão da assistência recebida de quem mais tinha condições de prestá-la - relações de dependência surgiram entre o grupo e a Mulher do médico que, comovida com a vulnerabilidade dos cegos diante do caos que havia se instalado também fora do manicômio, assumiu para si o compromisso de não largá-los as suas próprias sortes - ainda que ao leitor fosse muito fácil concluir que ela não teria responsabilidade alguma para com eles - e propôs guiar cada um dos cegos do grupo até suas respectivas casas, preocupando-se, inclusive, em encontrar roupas e sapatos para todos, pois, não poderiam andar por aí "sujos e rotos" (SARAMAGO, 2019, p. 229).

Além da manifestação de cuidado que a Mulher do médico teve para com os cegos, observa-se neles o estado de vulnerabilidade em que se encontravam, no simples ato de vestir roupas limpas e reconhecendo a vantagem de ter alguém que, além de encontrar vestes que lhes servissem, pudesse aconselhá-los sobre o que vestir:

[...] não obstante a relativa escassez da oferta, porque, como se costuma dizer, a fruta está muito escolhida, combinam bem umas com as outras, é vantagem de ter conosco alguém que nos aconselha, Veste tu isto, que vai melhor com essas calças, as riscas não jogam com as pintas, pormenores assim [....] (SARAMAGO, 2019, p. 231).

Por outro lado, ainda que desinteressadamente, um olhar mais atento poderia dizer que, ao escolher roupas que combinassem, a personagem vidente estaria impondo ao grupo um "padrão de comportamento". Todavia, no contexto do romance em comento, interpreta-se que referida passagem coloca sutilmente o leitor em contato com a representação figurativa da diferença entre dar assistência e dar dignidade à Pessoa Humana, pois, não se pode desconsiderar o óbvio: estavam todos cegos, os que flanavam pela rua, os que vagavam desatinados, o grupo, enfim, a população toda, então ninguém notaria a combinação das roupas.

Frustrada a tentativa de conduzir cada um dos cegos às suas casas, não por falta de vontade da personagem vidente, mas porque, dadas as circunstâncias, assim decidiu o grupo, a 
obra encaminha-se para o desfecho. O grupo segue para a residência do médico e sua esposa onde começam a se adaptar ao novo estilo de vida.

As cenas que se passam na residência provavelmente são as cenas em que mais se evidencia o sentimento singular de Humanidade - de Fraternidade - do grupo e principalmente da Mulher do médico. Quando seguros e, de certa forma, conformados com o estado de cegueira, as personagens passaram a planejar a adaptação à nova vida sob a liderança da Mulher do médico, que assumiu a responsabilidade de garantir-lhes uma vida com o máximo de dignidade possível, proferindo uma lição sobre como ainda haveria razão para buscar uma vida digna:

[...] não esqueçamos do que foi a nossa vida durante o tempo em estivemos internados, descemos todos os degraus da indignidade, todos, até atingirmos a abjecção, embora de maneira diferente pode suceder aqui o mesmo, lá ainda tínhamos a desculpa da abjecção dos de fora, agora não, agora somos todos iguais perante o bem e o mal, sabíamo-lo de cada vez que tivemos de agir no tempo em que a cegueira era uma exceção, o certo e o errado são apenas modos diferentes de entender a nossa relação com os outros [...] (SARAMAGO, 2019, p. 262)

Consubstanciando o que foi argumentado sobre os cegos estarem a redescobrir a própria Humanidade, cita-se uma fala do médico em que esta redescoberta resta bem evidente: "Se eu voltar a ter olhos, olharei verdadeiramente os olhos dos outros, como se estivesse a ver-lhes a alma [...]" (SARAMAGO, 2019, p. 262). E assim, encaminhando-se para o final da obra, esse parece ser o momento em que os cegos se dão conta de que o que os unia não era apenas o fato de estarem cegos ou de que estivessem, no início, lotados em uma mesma camarata, mas, o sentimento de serem todos Pessoas Humanas, então, quando o grupo se dá conta desse sentimento singular de Humanidade, todos voltam a enxergar, recobrando um a um a visão da mesma forma que haviam perdido.

Por fim, o que se conclui é que o desfecho da obra de José Saramago não é bem um desfecho, é tão somente o rumo a ser seguido, pois, a (re)construção da Sociedade - como se reergueria a Humanidade a partir daquele cenário - é deixada ao encargo do imaginário do leitor. Ao desconstruir a Sociedade, reduzir as personagens às suas essências, ceifar os direitos fundamentais e criar o pior cenário possível, o Autor provoca o leitor a refletir sobre o fato de que a ausência do sentimento de Humanidade ameaça a própria Humanidade.

Revista de Direito, Arte e Literatura | e-ISSN: 2525-9911 | Encontro Virtual | v. 6 | n. 2 | p. 38 - 56 | Jul/Dez. 2020. 
Nesse sentido, o Ensaio sobre a cegueira pode ser interpretado como uma parábola que se vale da cegueira como metáfora para transmitir o ensinamento sobre a Fraternidade, o valor da Fraternidade na (re)organização da convivência humana.

\section{CONSIDERAÇÕES FINAIS}

Este artigo cuidou de fazer uma dupla abordagem, literária e realista, com objetivo de identificar a presença da Fraternidade na obra Ensaio sobre a cegueira e analisar o grau de importância deste sentimento de singular Humanidade na organização da vida em comum, tanto no cenário literário, quanto frente à concretização da ameaça à Humanidade com a Pandemia da Covid-19, porque, surpreendentemente, a experiência vivida pelas personagens da obra afetou a organização da convivência humana e culminou de certa forma na desorganização da Sociedade, na desconstrução do modelo que era tido antes como "normal", assim como ocorreu no plano real com a Covid-19.

A importância da temática abordada consiste em revelar que a aptidão de sentir é necessária tanto na organização como na reorganização da convivência humana através da obra de José Saramago. A genialidade do Autor ajuda a perceber que, em uma situação extrema, na qual praticamente todos os direitos fundamentais são ceifados, apenas o sentimento de singular Humanidade - a Fraternidade - impede a falência total da Sociedade e, assim, a obra Ensaio sobre a cegueira se apresenta como uma parábola, uma metáfora sublime em que, apenas quando as personagens redescobrem esse sentimento comum é que todos recuperam a visão.

Da ficção para realidade, em um curto espaço de tempo, a Humanidade impactada pela pandemia causada pelo novo coronavírus - Covid-19 passou a vivenciar uma situação extrema, sendo colocada em uma posição de autocuidado que somente passou a ser efetiva na relação de reciprocidade, pois, cuidar apenas de si não seria suficiente para evitar a contaminação. Tornou-se, então, flagrante a necessidade de cuidado(s) também com o(s) outro(s):

Afinada a percepção da realidade, facilmente, compreende-se que, independentemente da organização da convivência estar ou não dominada pelo egoísmo, a aptidão de sentir é necessária nas relações sociais, porque essas são as

Revista de Direito, Arte e Literatura | e-ISSN: 2525-9911 | Encontro Virtual | v. 6 | n. 2 | p. 38 - 56 | Jul/Dez. 2020. 
referências que as Pessoas Humanas têm umas com as outras, mediadas pelos contextos e situações determinadas da(s) Sociedade(s) em que estão inseridas. VALE DA SILVA, BRANDÃO, 2017, p. 57).

A percepção da realidade provocada pela pandemia causada pelo novo coronavírus Covid-19, traz à tona a importância da presença da Fraternidade como base na (re)organização da convivência humana. A Fraternidade (PÉREZ TÁPIAS, IHU, 2020), deve ser o pano de fundo nessa crise pandêmica em que o apelo é pela Solidariedade:

[...] a solidariedade, tão em voga na crise atual, também precisa ser repensada a partir da noção de "comum" e da ideia de "fraternidade". "Apelamos muito à solidariedade, mas esse apelo é muitas vezes deixado em branco porque falta o pano de fundo de uma fraternidade verdadeiramente vivida: é a experiência de laços entre um e outro que nos compõe das profundezas. Os processos de subjetivação e a construção simbólica de identidades não são adequadamente implantados sem a consciência da irmandade do que nós, humanos, temos em comum”, [...]. (PEREZ TAPIAS, IHU, 2020).

Por certo que a Pandemia causada pelo novo coronavírus - Covid-19 - revelou à Humanidade sua vulnerabilidade e, paradoxalmente, o potencial positivo que pode ser extraído das inúmeras consequências que a posição de autocuidado não basta por si só e só faz sentido quando há reciprocidade do cuidado de si e com os outros.

E, nesse sentido, a Fraternidade se apresenta como redescoberta de "um valor republicano da vida em comum, que não só é tecido socialmente, mas também institui a política como um espaço comum de liberdade e participação.” (PEREZ TAPIAS, IHU, 2020), tornando-se um recurso superar as situações de crise pelo despertar do sentimento de singular Humanidade, torna-se condição de possibilidade na (re)organização da convivência humana.

Não há dúvidas que, assim, como a "Cegueira branca", a pandemia afetou e não se sabe por quanto tempo mais continuará afetando a vida de todos indistintamente e, seguramente, os impactos da Pandemia causada pelo novo coronavírus - Covid-19, abre espaço para um questionamento fático muito forte em relação a crise gerada por um modo de vida que ao "largo da modernidad se configuró hasta constituir el hábitat econômico de uma <<civilización occidental>> que exportó capitalismo al resto del mundo y, com él, también 
los gérmenes de sus crisis y no solo de su potencial económico"5. (PEREZ TAPIAS, 2019, p.108).

Afinada a percepção da realidade, facilmente compreende-se que, independentemente da organização da convivência estar ou não dominada pelo egoísmo - pelo individualismo - a aptidão de sentir é necessária nas relações sociais, porque essas são as referências que as Pessoas Humanas têm umas com as outras, mediadas pelos contextos e situações determinadas pela Sociedade em que estão inseridas.

Por fim, assim como a obra Ensaio sobre a cegueira pode ser interpretada como uma parábola, que se vale da cegueira como metáfora para transmitir o ensinamento sobre a Fraternidade - o valor da Fraternidade na (re)organização da convivência humana -, a Pandemia causada pela Covid-19 é a realidade que se apresenta à Humanidade e "impõe apostar na amizade, na Fraternidade e ter esperança" (RESTA, 2004, p.74), abrindo espaço para a presença da Fraternidade na organização da vida em comum, na convivência humana com sentido daquilo que realmente é inerente à existência com dignidade.

\section{REFERÊNCIAS DAS FONTES CITADAS}

ARENDT, Hannah. Homens em tempos sombrios. Tradução de Denise Bottmann. São Paulo: Companhia das Letras, 2008.

BAGGIO, Antonio Maria. La Fraternidad como Categoria Politica. In: PIETRO, Antonio Márquez (Coord.). Fraternidad y Justicia. Granada: Editorial Comares, 2012.

BAUMAN, Zygmunt. Modernidade líquida. Tradução de Plínio Dentzien. Rio de Janeiro: Jorge Zahar Ed., 2001.

BAUMAN, Zygmunt. Tempos líquidos. Tradução de Alberto Medeiros. Rio de Janeiro: Jorge Zahar Ed., 2007.

FONSECA, Reynaldo Soares da. O Princípio Constitucional da Fraternidade: Seu Resgate no Sistema de Justiça. - Belo Horizonte: Editora D’Plácido, 2019.

\footnotetext{
5 "Ao longo da modernidade configurou-se para constituir o habitat econômico de uma <<civilização ocidental > que exportava capitalismo para o resto do mundo e, com ele, também os germes de suas crises e não apenas seu potencial econômico. (PEREZ TAPIAS, 2019, p.108). Tradução nossa.
}

Revista de Direito, Arte e Literatura | e-ISSN: 2525-9911 | Encontro Virtual | v. 6 | n. 2 | p. 38 - 56 
INSTITUTO ANTÔNIO HOUAISS DE LEXICOGRAFIA. Minidicionário Houaiss Da Língua Portuguesa.- São Paulo: Moderna, 2019.

LOPES, João Marques. Saramago: biografia. São Paulo: Leya, 2010.

MENDES, Gilmar Ferreira; BRANCO, Paulo Gustavo Gonet. Curso de direito constitucional. - 13. ed. rev. e atual. - São Paulo: Saraiva Educação, 2018. - (Série IDP).

MORIN, Edgar. A Via: para o futuro da humanidade. Tradução de Edgard de Assis Carvalho, Mariza Perassi Bosco. Rio de Janeiro: Bertrand Brasil, 2013.

PASOLD, Cesar Luiz. Metodologia da pesquisa jurídica: teoria e prática. 14. ed. rev., atual. e ampl. Florianópolis: Empório Modara, 2018.

PÉREZ TAPIAS, Jose Antonio. O Homo Deus é uma fantasia perdida. A natureza humana se assenta no comum. Entrevista especial com José Antonio Perez Tapias. Trad. Patricia Fachin; Wagner Fernandes de Azevedo. 19 Mai 2020. Disponível em:

<www.ihu.unisinos.br/599062-o-homo-deus-e-uma-fantasia-perdida-a-natureza-humana-seassenta-no-comum-entrevista-especial-com-jose-antonio-perez-tapias.>. Acesso em: $21 \mathrm{de}$ mai 2020.

PÉREZ TAPIAS, Jose Antonio. SER HUMANO. Cuestión de dignidade en todas las culturas. Madrid: Editorial Trotta, 2019.

RESTA, Eligio. Direito Fraterno. Tradução de Sandra Regina Martini Vial. Santa Cruz do Sul: EDUNISC, 2004.

SARAMAGO, José. Autobiografia de José Saramago. Fundação José Saramago, 2008. Disponível em: <https://www.josesaramago.org/autobiografia-de-jose-saramago/>. Acesso em: 25 de jun 2020.

SARAMAGO, José. Ensaio sobre a cegueira. São Paulo: Companhia das Letras, 2019. 79a reimpressão.

VALE DA SILVA, Ildete Regina; BRANDÃO, Paulo de Tarso. CONSTITUIÇÃO E FRATERNIDADE. O Valor Normativo do Preâmbulo da Constituição. Curitiba: Juruá, 2015.

VALE DA SILVA, Ildete Regina; BRANDÃO, Paulo de Tarso. FRATERNIDADE E SOLIDARIEDADE: UMA CONTRIBUIÇÃO DA CONSTITUIÇÃO BRASILEIRA AO HUMANISMO. Publicado nos anais do $5^{\circ}$ Seminário Internacional "Democracia e Constitucionalismo: novos desafios na era da globalização". Università Degli Studi Di Perugia - Itália. Setembro de 2017. p. 38-56.

Revista de Direito, Arte e Literatura | e-ISSN: 2525-9911 | Encontro Virtual | v. 6 | n. 2 | p. 38 - 56 | Jul/Dez. 2020. 